\section{How good a model is the Fugu genome?}

J. Gilley et al. in Scientific Correspondence ${ }^{1}$ describe the organization of the pufferfish Surfeit locus in a letter entitled "Fugu genome is not a good mammalian model". The wide-ranging conclusions implied by this headline are not supported by the evidence and arguments presented.

First, Gilley et al. state that "[t]he only examples of significant conservation of gene order over short regions are in specialized loci such as the Hox loci, where genomic organization is believed to be critically related to developmental regulation". This is not true. M. K. Trower et al. have shown that conservation of synteny and gene order is seen in the c-fos locus ${ }^{2}$, where there is no reason to believe that linkage is constrained by function, and other examples are provided by G. Elgar ${ }^{3}$. Both of these papers were cited by Gilley et al. but their contents were not brought to readers' attention.

Second, we originally proposed the Fugu genome as a model because of its small size and because we showed that it had the same overall gene repertoire as the human genome. Subsequent work has confirmed these properties and the proposed model. We recognized early on that where conservation of synteny and gene order were found, there would be additional advantages for comparative positional cloning, but we have been careful not to make large claims for this. Determination of the extent of linkage conservation will be important for our understanding of the evolution of the vertebrate genome and will be a matter of direct observation rather than opinion based on a single example.

Samuel Aparicio

Wellcome/CRC Institute,

Tennis Court Road,

Cambridge CB2 1QR, UK

Sydney Brenner

Molecular Sciences Institute,

9894 Genesee Avenue,

La Jolla,

California 92037, USA

Gilley and colleagues ${ }^{1}$ present data on the Surfeit genes isolated from the Fugu genome. The Surfeit locus is of particular interest as the genes contained within are tightly packed in both mammals and the chicken and yet dispersed in invertebrates. Unfortunately, the data from Fugu do not support the conclusion drawn by Gilley et al. that Fugu is not a good mammalian genome model.

On the contrary, Fugu is a good model. All the Surfeit genes are present in the Fugu genome. The genes were isolated with "mammalian Surfeit gene complementary DNA probes", indicating that homology is sufficient to isolate Fugu homologues from mammalian cDNAs. The "homologues are all highly conserved at the amino-acid level and their gene structures are mostly identical to the mammalian genes". Gilley et al. also state that " $\mathrm{t}]$ he only examples of conservation of gene order over short regions are in specialized loci such as the Hox loci". But this is not true $e^{2,3}$. We are investigating several regions that demonstrate conserved synteny across unrelated genes. The scarcity of examples is due in part to the lack of absolute mammalian gene order data and in part to the lack of absolute Fugu data ${ }^{4}$.

In many cases, the most informative data are the differences between the genomes. The unique organization of the Surfeit locus in Fugu is an example of this, and data provide an opportunity to understand the evolution of this region.

To summarize, five of the six Surfeit genes fall into two syntenic groups in Fugu; one region covering the very tightly linked Surf-3, Surf-1 and Surf-6 genes and the other linking Surf-4 and Surf-2 with two other linked genes in man. A comparative mapping project covering the TSC1 region on $9 \mathrm{q} 34$, using the Fugu genome, is under way to address the issue raised by the authors in a more comprehensive manner.

It is true that some regions of Fugu and mammalian genomes will bear no relation to each other and gene order will be fragmented. In the case of the Surfeit locus, there is undeniably a degree of fragmentation, but there is also enough conserved synteny to generate informative data. It is unfortunate that Gilley et al. have created an impression that comparative genomics with $F u g u$, and perhaps with lower organisms generally, is not important - this is simply not the case.

Greg Elgar

Melody Clark

UK HGMP-Resource Centre,

Hinxton Hall,

Cambridge CB10 1SB, UK

e-mail: gelgar@hgmp.mrc.ac.uk

Andrew Green*

Richard Sandford ${ }^{\dagger}$

*Department of Medical Genetics,

and ${ }^{\dagger}$ Department of Medicine,

University of Cambridge,

Addenbrookes NHS Trust,

Hills Road

Cambridge CB2 2QQ, UK

\footnotetext{
1. Gilley, J., Armes, N. \& Fried, M. Nature 385, 305-306 (1997).

2. Trower, M. K. et al. Proc. Natl Acad. Sci. USA 93, 1366-1369 (1996).

3. Elgar, G. et al. Trends Genet. 12, 145-150 (1996).

4. How, G-F., Venkatesh, B. \& Brenner, S. Genome Res. 6 , 1185-1191 (1997).
}

\section{Aaaargh, no! - in lights}

Using the grisly example of a tiger-eaten tour guide, and the more subtle alarm pheromone of a pike-eaten minnow, Jared Diamond ${ }^{1}$ in News and Views discussed recent work $^{2}$ identifying one benefit of alarm calls - predator interference. In addition to the audible and olfactory alarm signals that he noted, there are the many visible ones, most notably the flashes produced by luminescent organisms finding themselves similarly in extremis.

These visible signals resulted in the 'burglar alarm' hypothesis, whereby secondary predators, either different species or larger conspecific cannibals, are alerted by the flash to potential prey in the form of the primary predator or grazer ${ }^{3}$. The firefly in the spider's web, the dinoflagellate in the copepod's grasp, the brittle star grabbed by the crab and the ctenophore bitten by the turtle all 'scream' visibly. The value of these responses (and the validation of the hypothesis) has recently been demonstrated by experiments in which non-luminous prey, swimming in the dark among luminous dinoflagellates, were directly targeted by secondary visual predators (both fish and squid) using the flashes of the dinoflagellates ${ }^{4,5}$.

Most of the oceanic environment is permanently dark (and much of the rest of it is dark during the night). A majority of marine individuals (and, in many taxonomic groups, most species) are luminous. Visible signals are probably the commonest alarm response in this habitat. Their success depends on the likelihood of a secondary predator within visible range, probably no more than a few tens of metres. Population densities decline logarithmically with depth, so primal flashing should be less effective at great depth, though it might still persist if it has a direct deterrent effect on the primary predator. Copepods eat fewer luminous dinoflagellates than non-luminous ones at similar densities, so the two effects can go hand in hand ${ }^{6,7}$.

I do not know whether a minnow alarm pheromone intimidates a pike, or whether a scream deters a tiger, but in neither individual case is the mechanism of the effect relevant, only its time constant.

Peter J. Herring

Southampton Oceanography Centre,

Empress Dock, Southampton SO14 3ZH, UK

e-mail:p.j.herring@soc.soton.ac.uk

\footnotetext{
1. Diamond, J. Nature 385, 295-296 (1997).

2. Chivers, D., Brown, G. \& Smith, J. Am. Nat. 148, 649-659 (1996)

3. Burkenroad, M. D. J. Mar. Res. 5, 161-164 (1943).

4. Mensinger, A. F. \& Case, J. F. Mar. Biol. 112, 207-210 (1992).

5. Fleisher, K. J. \& Case, J. F. Biol. Bull. 189, 263-271 (1995).

6. Esaias, W. E. \& Curl, H. C. Limnol. Oceanogr. 17, 901-906 (1972).

7. White, H. H. J. Exp. Mar. Biol. Ecol. 36, 217-224 (1979).
} 